\title{
Prognosis of Intravascular Large B Cell Lymphoma (IVLBCL): Analysis of 182 Patients from Global Case Series
}

This article was published in the following Dove Press journal: Cancer Management and Research

\section{Ziyue Liu' \\ Yuelun Zhang ${ }^{2}$ \\ Yicheng Zhu' \\ Wei Zhang ${ }^{3}$}

'Department of Neurology, Peking Union Medical College Hospital, Chinese Academy of Medical Sciences and Peking Union Medical College, Beijing, People's Republic of China; ${ }^{2}$ Central Research Laboratory, Peking Union Medical College Hospital, Chinese Academy of Medical Sciences and Peking Union Medical College, Beijing, People's Republic of China; ${ }^{3}$ Department of Hematology, Peking Union Medical College Hospital, Chinese Academy of Medical Sciences and Peking Union Medical College, Beijing, People's Republic of China
Correspondence: Wei Zhang Department of Hematology, Peking Union Medical College Hospital, Chinese Academy of Medical Sciences and Peking Union Medical College, No. I

Shuaifuyuan, Wangfujing, Beijing 100730,

People's Republic of China

Tel +86 I368I473557

Email vv1223@vip.sina.com
Purpose: This study provides an overview of the prognosis of intravascular large B cell lymphoma (IVLBCL) over the past 10 years and analyzes the possible relevant factors.

Patients and Methods: We conducted a literature search of case reports, case series, and retrospective studies of IVLBCL published from January 2008 to July 2018. After excluding inappropriate data, 103 publications were selected for the analysis. Statistical analyses of different treatment modalities, the effect of blood-brain barrier (BBB)-penetrating drugs, and prognostic factors for outcomes were performed.

Results: In total, 182 pathologically confirmed cases of IVLBCL were included in our study. The results revealed that the 1 - and 3-year overall survival rates were 42.3 and $11.5 \%$, respectively, whereas the median overall survival was 340 days. Overall survival (450 days vs 180 days) and progression-free survival (420 days vs 150 days) were significantly longer in patients who received rituximab-containing regimens than in those treated with other regimens. For IVLBCL involving the CNS, regimens containing BBB-penetrating drugs failed to provide an additional survival benefit. In addition, lactic dehydrogenase levels $\geq 700 \mathrm{U} / \mathrm{L}$, CNS involvement, and hemophagocytic syndrome were identified as unfavorable risk factors in patients with IVLBCL, whereas skin involvement appeared to be a protective factor.

Conclusion: Rituximab-containing chemotherapy can improve the outcomes of patients with IVLBCL, but the prognosis remains unsatisfactory. Treatment regimens containing BBB-penetrating drugs failed to improve outcomes in patients with CNS-involved IVLBCL. Several factors affect the prognosis of patients with IVLBCL, and further research on the underlying mechanisms is needed.

Keywords: lymphoma, B cell, rituximab, central nervous system, blood-brain barrier, methotrexate

\section{Introduction}

Intravascular large B cell lymphoma (IVLBCL) is defined as a rare type of extranodal large B cell lymphoma that is characterized by the selective growth of lymphoma cells within the lumina of vessels. ${ }^{1}$ Under the microscope, the neoplastic lymphoid cells are mainly large cells with prominent nucleoli and frequent mitotic figures, lodged in the lumina of small or intermediate-sized vessels. ${ }^{1,2}$ Though the reason why tumor proliferation is confined to the vascular lumen remains unclear, it is speculated to be related to lack of leukocyte adhesion molecules or deficiency in the Hermes-3-defined homing receptor antigen, leading to hindered lymphocyte 
homing and transvascular migration. ${ }^{3}$ This mechanism differs from those of most other large B cell lymphomas, and it leads to unique clinical presentations and probably different prognoses. IVLBCL is often associated with rapid deterioration and unfavorable outcomes, and diagnosis can be delayed owing to its heterogeneous clinical manifestations and a lack of specific biomarkers at an early stage. ${ }^{4,5}$ Moreover, the treatment protocol for patients with IVLBCL has been widely debated, varying widely among real-world patients. ${ }^{6}$

The past 10 years have witnessed rapid development in the treatment of cancer, including lymphoma. ${ }^{7,8}$ However, there is no consensus on the treatment of IVLBCL because no large clinical trials have been conducted. In 2008, Shimada et al analyzed 106 patients with intravascular lymphoma (IVL) from 17 centers in Japan and reported that patients receiving rituximab-containing chemotherapy had higher 2-year survival rates than those receiving other treatments (66\% vs 46\%). ${ }^{9}$ Subsequently, rituximab has been considered a strong candidate for the treatment of IVLBCL. However, the treatment and outcomes of the disease in the real world have scarcely been reported on a global basis. To address this issue, we aimed to thoroughly review cases of IVLBCL published in the past decade, hoping to obtain an objective and comprehensive overview of the current status of treatment and outcomes.

Based on previous reports, $27-42 \%$ of patients with IVLBCL experienced CNS symptoms during the course of the disease, particularly in non-Asian populations. ${ }^{10,11}$ Among them, only $7.61 \%$ of patients presented with stroke-like syndrome, whereas most patients presented symptoms and imaging features indicating brain parenchyma involvement, such as overall cognitive decline, seizures, and brain masses, which were sometimes confirmed pathologically. ${ }^{11,12}$ Although IVLBCL with CNS presentation is often associated with rapid progression and poor outcomes, ${ }^{11,13}$ there is no special protocol for this malignancy compared with IVLBCL involving other organs. BBB-penetrating drugs such as methotrexate (MTX) have been important components of treatment regimens for CNS lymphomas. ${ }^{14}$ However, they were not specifically recommended for patients with IVLBCL with CNS symptoms despite the risk of extravascular invasion into the brain parenchyma. Thus, we specifically examined the treatment and outcomes of all cases of IVLBL with CNS involvement reported in the past decade, aiming to determine whether BBB-penetrating drugs improve outcomes.
Considering the high heterogeneity of the disease, many factors such as age, lactic dehydrogenase (LDH) levels, and involved organs may affect prognosis. Age, CNS involvement, and serum LDH levels were proposed as three major prognosis factors for poor outcomes in a meta-analysis of 740 patients with IVL treated between 1959 and 2011, during which rituximab treatment was not popular. ${ }^{15}$ Therefore, we analyzed other possible prognostic factors, verified several previously proposed factors, and further explored the effects of these factors in rituximab-treated patients. We hope our work provides deeper insights into the course of the disease and the impact of rituximab treatment.

\section{Patients and Methods}

\section{Literature Search and Selection}

We conducted a comprehensive literature search of the electronic databases through PubMed, Embase, Cochrane Library and Web of Science (from January 2008 to July 2018) using the following search terms: "Lymphoma, Large B-Cell, Diffuse" with "Brain Diseases" or "Nervous System"; "intravascular" with "lymphomatosis" or "lymphoma"; "Endotheliomatosis"; and "large cell lymphoma" with "angiotrophic" or "angiotropic". Furthermore, we reviewed reference lists of retrieved publications to search for more case reports. We selected all case reports, case series and retrospective studies with newly reported cases in the past ten years, that were written in English, Japanese or Chinese (with English reviews). Studies were excluded if the diagnosis, pathological records, disease progression, and outcome data were insufficient or they were nonhuman cases. If multiple reports described the same patients, we included only the ones with the most abundant available information. The Flow diagram of inclusion criteria is shown in Figure 1.

\section{Data Extraction}

We extracted multiple data from the publications, including the year of publication, age, gender, geography subtypes, involved organs, clinical presentations, immuno-histological markers, LDH level, Ann Arbor stage, diagnose methods, treatment programs, the response of treatment and survival times. Involved organs were confirmed by symptoms, lab tests, and typical pathological findings.

Survival data was obtained by extracting the time point of initial presentation, diagnosis, treatment, disease progression, relapse, death, and end of follow-up of each case from 


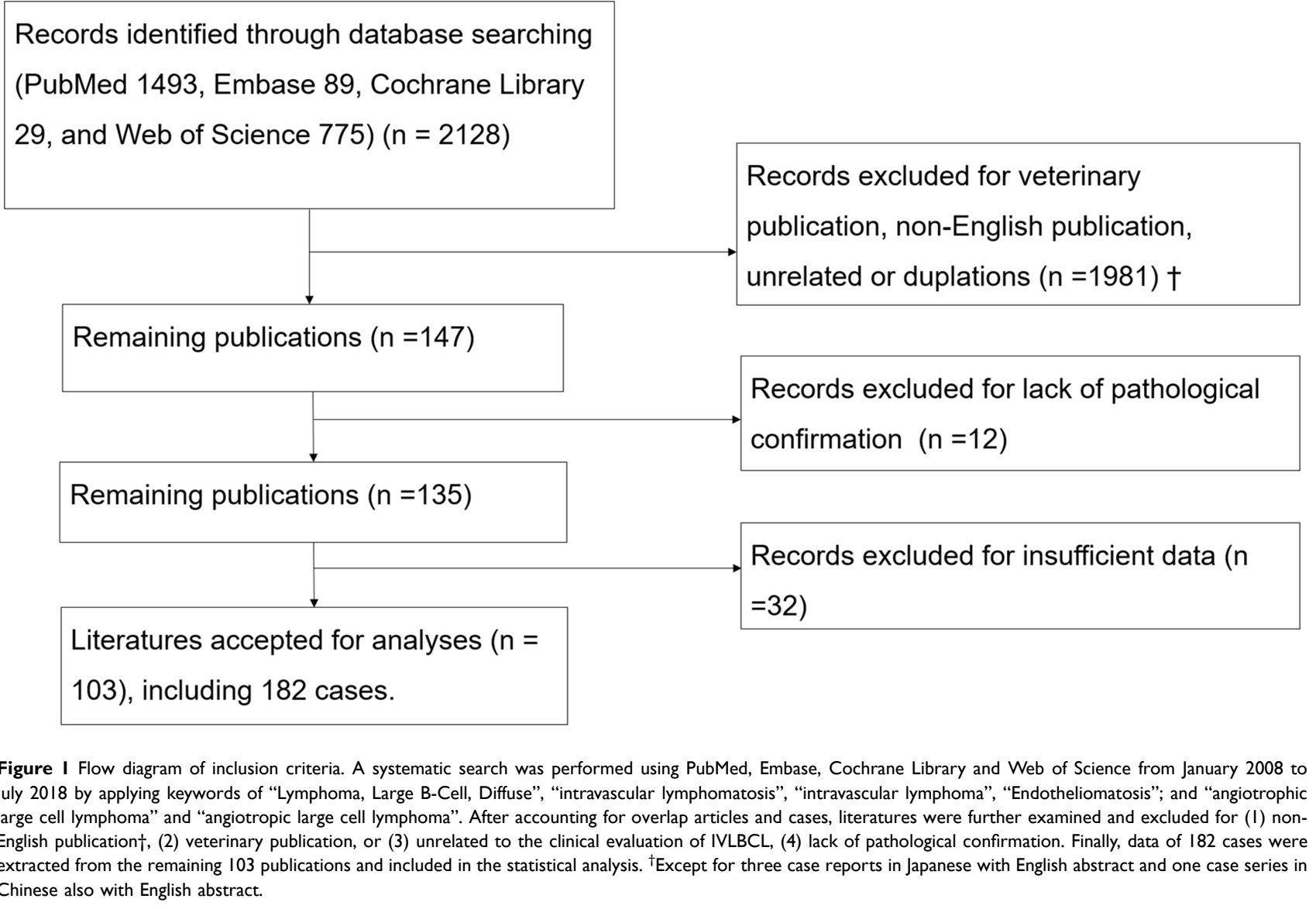

the publications, then the two epochs defined below were calculated. If the publication provided the survival times information rather than exact time points to do the calculations, the survival times matching the definition of the following two epochs were extracted. Survival times were divided into two epochs: (1) Overall survival (OS), defined as the time from initial presentation of symptoms to death (also applied for those who diagnosed post-mortem), (2) Progression-free survival (PFS), defined as the time from diagnosis (for patients with no treatment) or from treatment (for patients with treatment) to first day of disease progression, relapse, death or last date of follow-up (PFS data is unavailable for those who diagnosed post-mortem). This OS definition is not the same as most previous publications. But considering the interval from disease onset to hospital admission is highly varied and affected by complex factors in different cases, we believed that this definition of OS would better reflect the outcome of the disease.

\section{Statistical Methods}

The characteristics of patients were presented as number (percentage) or median (standard deviation).

\section{Evaluation of Treatment Modalities}

Patients were grouped according to treatment programs, namely $\mathrm{N}$ group=no treatment, $\mathrm{S}$ group=steroid only, $\mathrm{CT}$ group $=$ chemotherapy without rituximab, R-CT group $=$ chemotherapy with rituximab, and detailed treatment modalities of each group of patients were listed. We excluded five cases for lack of abundant treatment data for grouping. Next, 32 cases that diagnosed postmodern were further excluded in the analysis of PFS data. Group comparisons of the survival data parameters, including 1-year and 3-year survival rate, OS and PFS, were analyzed using the multivariable logistic regression or multivariable Cox regression based on the data type. Multiple adjust models were applied to balance the characteristics between groups: Model1 adjusted for age and gender; Model 2 additionally adjusted for the diagnostic method (post postmortem or not) and patient source (from single case reports and small case series or large case series). We chose those co-variates for the following two reasons: (1) previous research reported that age, CNS involvement, and LDH level may largely affect the outcome (we give up LDH for too many missing values and non-significant 
differences of distribution between groups), and (2) we noticed potential huge impact of diagnostic method and patient source on outcome parameters (patients characteristics of each diagnose method groups and patient source groups were provided in Supplementary Tables 2 and 3). Model 2 was not applied to $\mathrm{N}$ vs $\mathrm{S}$ group comparison because the sample size was not large enough. Moreover, a Mantel-Cox Log Rank test between the treatment groups was computed independently, and a Kaplan-Meier survival plot was then generated.

\section{Evaluation of BBB-Penetrating Drugs in CNS-IVLBCL}

CNS-IVLBL is recognized as IVLBL patients with CNS involvement and meet one of the following: (1) confirmed by brain-pathologically; or (2) the CNS lesions cannot be explained by causes other than IVLBCL. We further divided CNS-IVLBL cases into two categories: (1) nonisolated CNS-IVLBL, defined as patients meet the standard of CNS-IVLBCL and have other organs involvement with pathological confirmation, and (2) isolated CNSIVLBL, defined as IVLBL patients with pathological confirmed CNS involvement and no clinical presentations, laboratory or histological evidence of any other organs' involvement at the start of treatment. Next, we analyzed the outcome parameters of BBB-penetrating drugs treatment vs the negative counterpart in the total and each category of CNS-IVLBCL cases respectively, using univariant logistic regression or Fisher' exact test based on the data type. The analysis was also stratified by rituximab (R)-containing treatment or not (we omitted stratified analysis within non-R-treatment groups for there were little outcome differences among $\mathrm{N}, \mathrm{S}$ and $\mathrm{CT}$ groups, detailed in Supplementary Table 1). Although 29 CNS-IVLBL cases were diagnosed postmortem, most of them were treated by steroids or chemotherapy with or without rituximab for presumed vasculitis or other tumors. Thus, we did not exclude those cases.

\section{Evaluation of Prognostic Factors of Outcomes}

Potential prognostic factors were evaluated using univariate Cox regression (enter) to investigate their impact on patient survival outcomes. In the light of previous studies, univariate analysis results and treatment groups comparison results (Supplementary Table 1), we chose several factors to further enter a multivariate Cox regression test: age $\geq 70 y, L D H \geq 700 \mathrm{U} / \mathrm{L}$, skin, $\mathrm{CNS}$, and bone marrow (BM) involvement and haemophagocytic syndrome (HPS). All the above analysis was stratified by treatment modalities (rituximab-containing treatment or not). The P-value, Hazard Ratio (HR) and confidence interval (Cl) were calculated and presented graphically. We excluded five patients in the univariate Cox regression test for missing treatment data, and further excluded 49 other patients in multivariate analysis for missing data of LDH and organs involvement data (detailed analysis of the missing data is showed in Supplementary Table 5).

Statistical analyses were performed with IBM SPSS Statistics 25 software. A two-sided P value less than 0.05 was regarded as statistically significant. Bonferronicorrected threshold was applied in calculation of multiple comparisons.

\section{Results}

\section{Patient Characteristics}

In total, 182 cases of IVLBCL published in 103 studies between 2008 and 2018 were included in the present analysis (Supplementary Table 7), and patient characteristics are listed in Table 1. All patients were diagnosed via organ tissue biopsy $(\mathrm{n}=150,82.4 \%)$ or postmortem autopsy $(\mathrm{n}=$ $32,17.6 \%$ ). The median patient age was $64 \pm 12.7$ years, and $51.1 \%$ of patients were male. The most frequently involved organs included the nervous system $(\mathrm{n}=94$, $51.6 \%)$, bone marrow $(\mathrm{n}=73,40.1 \%)$, lungs $(\mathrm{n}=56$, $30.8 \%)$, and skin $(\mathrm{n}=36,19.8 \%)$. The median survival time of the patients was 340 days, whereas the 1- and 3 -year survival rates were $42.3 \%$ and $11.5 \%$, respectively.

\section{Comparisons of Outcomes Between Treatment Groups}

The treatment protocols of 177 patients as detailed in the literature were divided into four groups, termed the $\mathrm{N}(\mathrm{n}=$ $35,19.2 \%), \mathrm{S}(\mathrm{n}=15,8.2 \%), \mathrm{CT}(\mathrm{n}=24,13.2 \%)$, and R-CT groups $(\mathrm{n}=103,56.6 \%)$. In the $\mathrm{CT}$ and $\mathrm{R}-\mathrm{CT}$ groups, CHOP and R-CHOP were the most widely applied therapies, respectively (details are listed in Table 2).

A comparison of outcomes by treatment group is presented in Table 3. No significant differences in survival parameters were observed between the $\mathrm{N}$ and $\mathrm{S}$ groups. Comparing the $\mathrm{CT}$ and $\mathrm{R}-\mathrm{CT}$ groups, the 1-year survival rate was higher in the latter group $(29.2 \%$ vs $60.2 \%$; odds ratio $=0.214 ; 95 \%$ confidence interval $[\mathrm{CI}]=0.077-0.597$; $\mathrm{P}=0.003$, adjusted for age and sex). Overall survival (OS; 
Table I Characteristics of Patients (Total $n=\mid 82$ )

\begin{tabular}{|c|c|}
\hline Characteristics & No (\%) or Median (SD) \\
\hline $\begin{array}{l}\text { Age at diagnosis (years) } \\
\text { Male } \\
\text { Serum LDH level (U/L) } \\
\text { Ann Arbor stage IV* } \\
\text { AIVL }^{+}\end{array}$ & $\begin{array}{l}64(12.70) \\
93(51.1 \%) \\
954.5(2268.07) \\
83(45.6 \%) \\
52(28.6 \%)\end{array}$ \\
\hline $\begin{array}{l}\text { Clinical manifestations } \\
\text { "B” symptoms } \\
\text { NS } \\
\text { CNS } \\
\text { BM involvement } \\
\text { Lung } \\
\text { HPS } \\
\text { Anemiał } \\
\text { Splenomegaly } \\
\text { Skin } \\
\text { Hepatomegaly } \\
\text { Liver } \\
\text { Kidney } \\
\text { Adrenal gland } \\
\text { PNS } \\
\text { Heart } \\
\text { Spleen }\end{array}$ & $\begin{array}{l}97(53.3 \%) \\
94(51.6 \%) \\
89(48.9 \%) \\
73(40.1 \%) \\
56(30.8 \%) \\
51(28.0 \%) \\
51(28.0 \%) \\
43(23.6 \%) \\
36(19.8 \%) \\
25(13.7 \%) \\
17(9.3 \%) \\
15(8.2 \%) \\
15(8.2 \%) \\
14(7.7 \%) \\
14(7.7 \%) \\
10(5.5 \%)\end{array}$ \\
\hline $\begin{array}{l}\text { Immunophenotype } \\
\text { GCB } \\
\text { Non-GCB } \\
\text { NA }\end{array}$ & $\begin{array}{l}4(2.2 \%) \\
172(94.5 \%) \\
6(3.3 \%)\end{array}$ \\
\hline Diagnosed postmortem & $32(17.6 \%)$ \\
\hline $\begin{array}{l}\text { Outcome } \\
\text { I-year survival } \\
\text { 3-year survival } \\
\text { Survival time from onset to death, days }\end{array}$ & $\begin{array}{l}77(42.3 \%) \\
21(11.5 \%) \\
340(763.79)\end{array}$ \\
\hline
\end{tabular}

Notes: *Ann Arbor stage IV was defined as "Diffuse or disseminated involvement of I or more extra lymphatic organs or tissues with or without associated lymph node enlargement" 'Diagnostic criteria of Asian variant of intravascular large B-cell lymphoma: (I) At least two of three of the following clinical and laboratory criteria: cytopenia (hemoglobin $<11 \mathrm{~g} / \mathrm{dL}$, or $\mathrm{RBC}<350 \times 10^{4} / \mathrm{L}$, and/or platelet count $<10$ $\times 10^{4} / \mathrm{L}$ ); hepatomegaly and/or splenomegaly; absence of overt lymphadenopathy and tumor formation; and (2) all three of the following histopathologic criteria: erythrocyte-hemophagocytosis; immunophenotypic evidence of proliferating neoplastic B cells with large-cell morphology; pathologic findings of intravascular proliferation and/or sinusoidal involvement of lymphoma cells. ${ }^{\ddagger}$ Hemoglobin $<11 \mathrm{~g} / \mathrm{dL}$ or red blood cell count $<50 \times 10^{4} / \mathrm{L}$. ${ }^{\S} \mathrm{GCB}$ was defined as at least one of two of the following Immunophenotype: CD20(+), CDI0(+); CD20(+), CDI0(-), Mum-I(-), BCL-6(+). Non-GCB was defined as the following Immunophenotype:CD20(+), CDI0(-), Mum-I(+), BCL-6(+)/(-). Insufficient data for analysis or not appliable. Abbreviations: LDH, lactate dehydrogenase; NS, nervous system; CNS, central nervous system; PNS, peripheral nervous system; BM, bone marrow; HPS, haemophagocytic syndrome; AIVL, Asian variant of intravascular large B-cell lymphoma; GCB, germinal center B-like; Non-GCB, none-germinal center B-like.

450 days vs 180 days; $\mathrm{P}<0.001$, adjusted for age and sex) and progression-free survival (420 days vs 150 days; $\mathrm{P}<$ 0.001 , adjusted for age and sex) were also longer in the R-CT group than in the CT group, indicating the
Table 2 Details of Treatment Groups

\begin{tabular}{|l|l|l|}
\hline Treatment Modalities & No. & $\%$ \\
\hline N (Overall) & 35 & 19.2 \\
\hline S (Overall) & 15 & 8.2 \\
Intravenous methylprednisolone therapy, 3-5 days & 9 & 60.0 \\
Prednisolone orally & 1 & 6.7 \\
NA & 5 & 33.3 \\
\hline CT (Overall) & 24 & 13.2 \\
CHOP & 9 & 37.5 \\
CHOP+others & 4 & 16.7 \\
Others & 9 & 37.5 \\
NA & 2 & 8.3 \\
\hline R-CT (Overall) & 103 & 56.6 \\
R-CHOP & 57 & 55.3 \\
Others & 46 & 44.7 \\
\hline NA & 5 & 2.8 \\
\hline
\end{tabular}

Abbreviations: $\mathrm{N}$, none treatment group; $\mathrm{S}$, steroid treatment group; $\mathrm{CT}$, chemotherapy treatment group without rituximab; R-CT, rituximab containing chemotherapy treatment group; CHOP, cyclophosphamide, doxorubicin, vincristine, and prednisone; R-CHOP, rituximab, cyclophosphamide, doxorubicin, vincristine, and prednisone; NA, not available.

overwhelming superiority of rituximab-containing treatment. The difference remained significant after adjusting for CNS involvement, method of diagnosis, and patient source. The results of the Mantel-Cox Log rank test were similar ( $\mathrm{N}$ vs $\mathrm{S}$ group, $\mathrm{P}=0.971$; $\mathrm{CT}$ vs $\mathrm{R}-\mathrm{CT}$ group, $\mathrm{P}=0.001$ ). Kaplan-Meier survival curves for all 177 patients and each treatment group are presented in Figure 2.

\section{Effect of BBB-Penetrating Drugs in Patients with IVLBCL and CNS}

\section{Involvement}

In total, 88 cases of IVLBCL with CNS involvement were recognized, including 45 non-isolated and 43 isolated cases. In total, $11(12.5 \%)$ patients were treated using BBB-penetrating drugs (five non-isolated and six isolated cases, all of which included MTX treatment, Supplementary Table 5), whereas the remaining patients did not receive such drugs. Rituximab was applied in $45.5 \%$ of non-MTX-treated patients and $90.9 \%$ MTXtreated patients $(\mathrm{P}=0.007)$.

Subsequently, we further investigated the role of BBBpenetrating drugs such as MTX in the treatment of CNSinvolved IVLBCL (Table 4). Treatment with regimens including BBB-penetrating drugs did not result in higher complete response rates $(63.6 \%$ vs $36.4 \% ; \mathrm{P}=0.163)$ or 


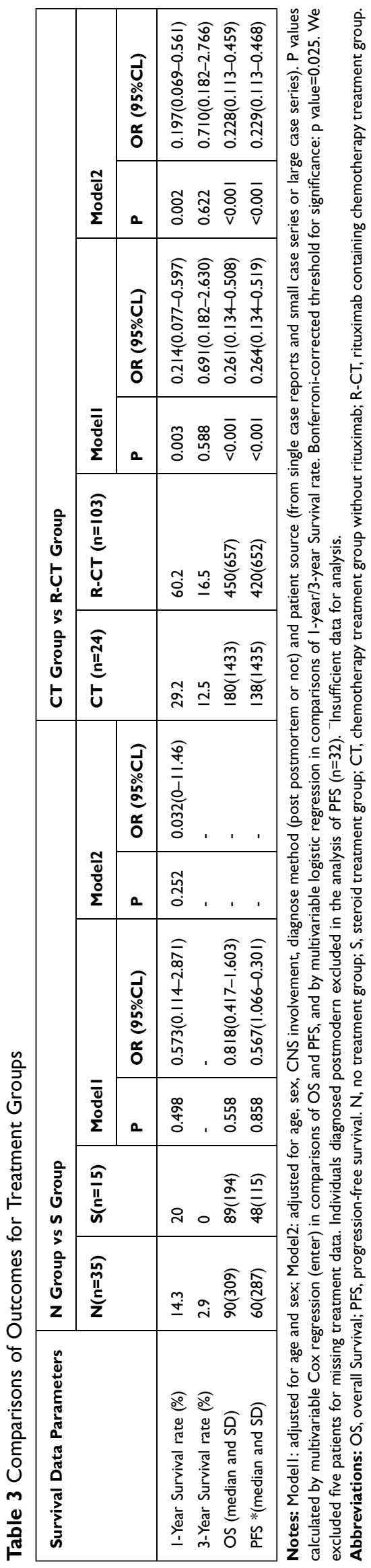

longer OS (369 days vs 210 days; $\mathrm{P}=0.144)$. Analysis of non-isolated and isolated cases of CNS-involved IVLBCL also revealed that survival did not differ according to the receipt of MTX. This result did not support the idea that BBB-penetrating chemotherapy improves outcomes in patients with IVLBCL with CNS involvement.

\section{Prognostic Factors for Outcomes}

The result of stratified analyze of predictive factors of time from onset to death was shown in Table 5 .

First, we analyzed possible prognostic factors, stratified by treatment groups, in a univariate model. Only hemophagocytic syndrome (HPS) was identified as a prognostic factor for poor outcomes in the R-CT group (hazard ratio $[\mathrm{HR}]=1.295 ; 95 \% \mathrm{CI}=1.058-1.585 ; \mathrm{P}=0.012$ ). Other factors including gender, age, Asian variant, LDH levels, skin, and CNS and bone marrow involvement were not predictive of outcomes.

In light of the results of previous studies, univariate analysis, and comparisons between treatment groups (Supplementary Table 1), we subsequently analyzed age, LDH levels, skin, CNS and bone marrow involvement, and HPS as potential predictive factors in a multivariate Cox regression model. The results illustrated that CNS involvement was a robust predictive factor for shorter survival $(\mathrm{HR}=2.234 ; 95 \% \mathrm{CI}=1.058-4.715 ; \mathrm{P}=$ 0.035 ), and the effect was not weakened by R-CT treatment. The prognostic effect of LDH levels was not as strong as that in previous studies, and it was only significant in the non-R-CT group ( $\mathrm{HR}=4.101 ; 95 \% \mathrm{CI}=$ 1.233-13.644; $\mathrm{P}=0.021$ ). In addition, the prognostic effect of HPS remained significant in the R-CT group, although the HR was close to 1. Skin involvement was recognized as a protective factor in the non-R-CT group $(\mathrm{HR}=0.256 ; 95 \% \mathrm{CI}=0.072-0.903 ; \mathrm{P}=0.034)$, but not in the R-CT group or unstratified analysis.

Patients who were excluded because of missing data $(\mathrm{n}=49)$ in the multivariate analysis tended to be younger, exhibit shorter OS, and have a greater likelihood of being enrolled in large series compared with patients included in the analysis (Supplementary Table 6), which may have slightly hindered us from identifying more prognostic factors.

\section{Discussion}

IVLBCL is a rare disease with a polymorphic presentation, and it was mainly described in case reports and case series, which contain essential patient data for analysis. Guided by 

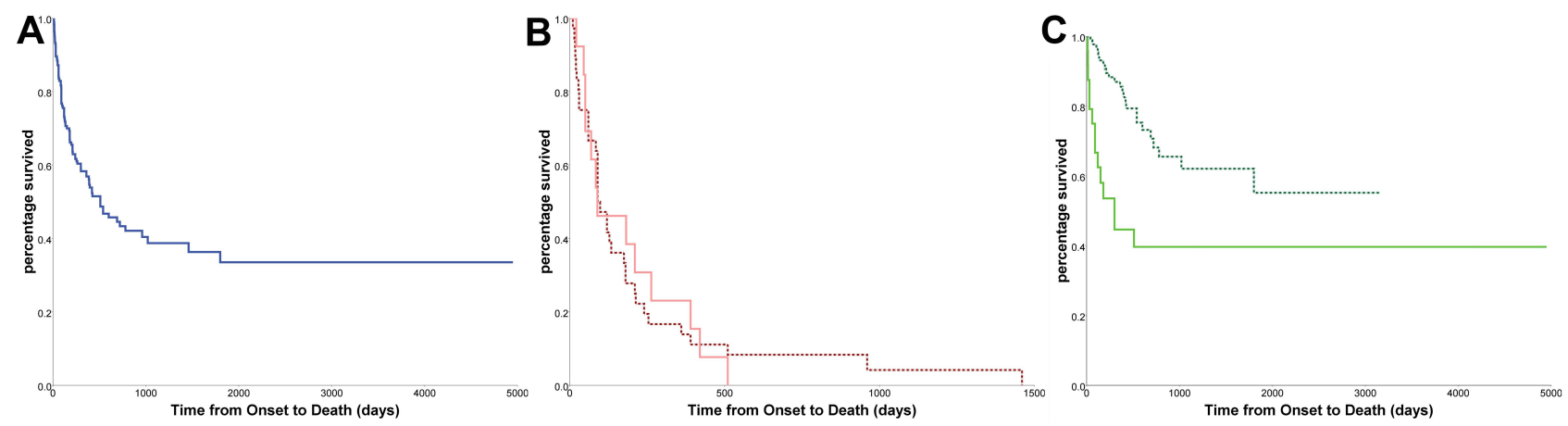

Figure 2 Kaplan-Meier Survival curves for Treatment Groups (individuals diagnosed postmodern excluded). (A) Kaplan-Meier Survival curve for all cases (5 cases were excluded for missing treatment data). (B) Kaplan-Meier Survival curves for N group (solid line) vs S groups (dotted line). P value of Mantel-Cox Log Rank test: 0.97I. (C) Kaplan-Meier Survival curves for CT group (solid line) vs R-CT groups (dotted line). P value of Mantel-Cox Log Rank test: 0.00 I.

Abbreviations: $\mathrm{N}$, none treatment group; $\mathrm{S}$, steroid treatment group; $\mathrm{CT}$, chemotherapy treatment group without rituximab; R-CT, rituximab containing chemotherapy treatment group.

the idea that literature reviews are effective for obtaining a global view of this disease, we thoroughly summarized IVLBCL cases published in the past decade with an emphasis on treatment and outcome data.

In our research, OS was significantly longer in the R-CT group than in the CT group, suggesting an important role for rituximab in the treatment of IVLBCL. In patients with CNS-involved IVLBCL, the application of BBBpenetrating chemotherapy did not improve outcomes. Furthermore, LDH levels $\geq 700 \mathrm{U} / \mathrm{L}$, CNS involvement, and HPS were identified as risk factors for poor outcomes in patients with IVLBCL, whereas skin involvement appeared to be a protective factor in patients who were not treated with rituximab.

Our study verified the superiority of rituximabcontaining chemotherapy from a global view, which is not surprising in this era. This result is in accordance with that of Shimada's retrospective study of 106 patients with IVL in Japan. ${ }^{9}$ In both studies, R-CHOP or R-CHOPlike regimens were the most commonly applied treatments. In our research, the median OS was 340 days, and 57.7\% patients died within the first year after onset, indicating that no improvement was achieved compared with survival data reported 10 years ago. Although R-CHOP is the most commonly used regimen, no standard treatment strategy exists, and no system for assessing response has been specifically designed for IVLBCL. Thus, further research is urgently needed to resolve these issues.

Unlike other lymphomas of the CNS, ${ }^{14,16}$ BBBpenetrating drugs, such as MTX and cytarabine, are rarely included in chemotherapy regimens for CNS-involved IVLBCL. As the number of patients treated with BBBpenetrating drugs was small, our analysis failed to reach a definitive conclusion. However, the finding that BBBpenetrating drugs provide no additional benefit did not contradict our theoretical speculation. This can reasonably be explained by the pathogenic mechanism of CNSinvolved IVLBCL, which is vessel occlusion rather than brain parenchyma lesions. ${ }^{5,17}$ Debate exists on this issue. Specifically, some patients have clinical features such as overall cognitive decline and seizures that may be related to brain parenchyma involvement (symptoms of CNSinvolved IVLBCL are summarized in Supplementary Table 4), whereas mass-like lesions, which are usually gadolinium-enhanced on T1-weighted images, were described as one of the five typical characteristics on magnetic resonance imaging and reported in several cases. ${ }^{12}$ However, these findings do not serve as definitive evidence of the extravascular dissemination of lymphoma cells because the symptoms can be otherwise explained by the wide distribution and small diameters of occluded vessels, resulting in extensive cortical dysfunction. In our study, only two patients had brain mass lesions, and extravascular invasion was not mentioned in the pathological report of either patient. ${ }^{18,19}$ Overall, for patients with IVLBCL with CNS involvement, the risk of parenchymal brain invasion remains unknown, and the mechanism by which tumor cells penetrate the BBB has not been fully clarified. Therefore, the use of MTX treatment is not recommended because of the lack of supporting evidence.

In the analysis of prognostic factors, our results are not fully consistent with previous findings. CNS involvement and LDH levels $(\geq 700 \mathrm{U} / \mathrm{L})$, which are usually related with severe dysfunction and a large tumor burden, are stable factors predicting poor outcomes. Conversely, the prognostic power of age ( $>70$ years) did not reach 


\begin{tabular}{|c|c|c|c|c|c|c|c|c|c|c|c|c|c|c|c|c|}
\hline \multirow{5}{*}{ 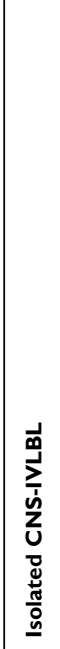 } & 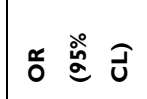 & & & & . & ' & . & . & . & ' & . & . & & 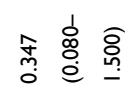 & 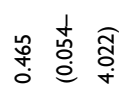 & 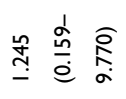 \\
\hline & $a$ & \multicolumn{3}{|l|}{ 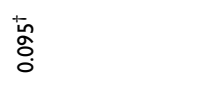 } & 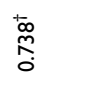 & : & . & ț & $\stackrel{+}{\circ}$ & . & 㐫 & 畜 & . & 黛 & 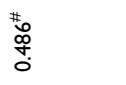 & 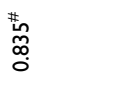 \\
\hline & 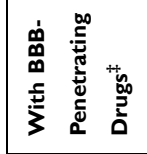 & $\circ$ & in & - & 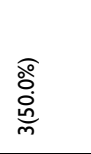 & 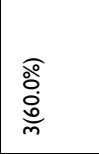 & 0 & 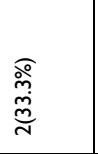 & 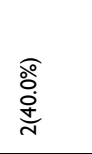 & $\circ$ & 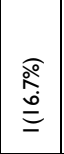 & 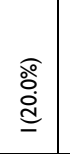 & 0 & 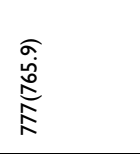 & 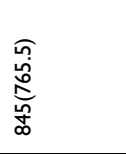 & $\stackrel{\propto}{\underline{0}}$ \\
\hline & 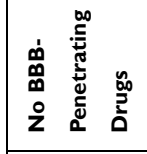 & $\hat{m}$ & $\underline{-}$ & $\bar{N}$ & 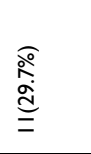 & 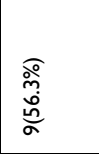 & ֻั & 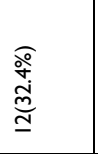 & 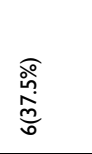 & 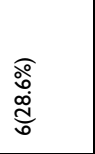 & 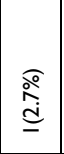 & 。 & 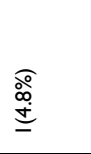 & 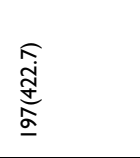 & 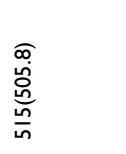 & 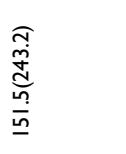 \\
\hline & 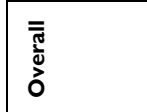 & 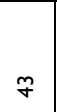 & $\bar{N}$ & $\pi$ & 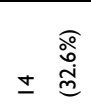 & 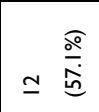 & 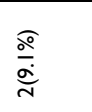 & 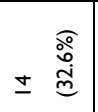 & $\infty \stackrel{\substack{\frac{\sigma}{0} \\
\stackrel{\infty}{m}}}{n}$ & $\circ \stackrel{\substack{\stackrel{\circ}{\circ} \\
=}}{=}$ & 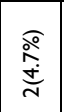 & 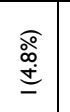 & 寉 & 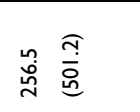 & 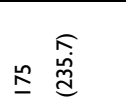 & 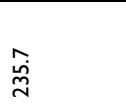 \\
\hline \multirow{5}{*}{ 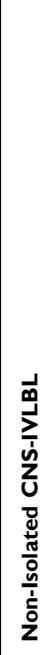 } & 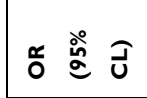 & & & & ' & & . & . & . & ' & . & , & , & 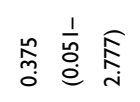 & 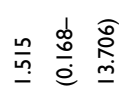 & . \\
\hline & a & \multicolumn{3}{|l|}{ 产 } & 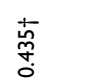 & 高 & . & 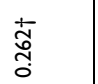 & 高 & . & 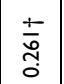 & 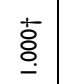 & . & 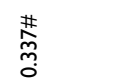 & $\frac{\#}{\stackrel{\#}{\hat{N}}}$ & . \\
\hline & 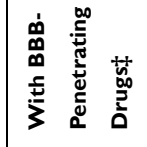 & in & in & 0 & $\begin{array}{l}\widehat{\circ} \\
\stackrel{0}{\dot{0}} \\
\stackrel{o}{\sigma}\end{array}$ & 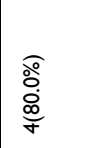 & . & 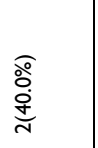 & 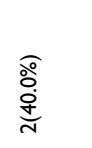 & . & 0 & 0 & 0 & 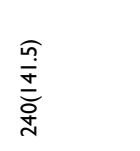 & 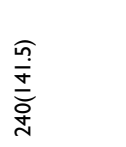 & . \\
\hline & 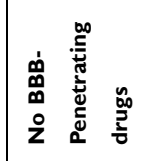 & o & $\underline{\underline{O}}$ & $\bar{N}$ & 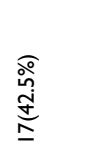 & 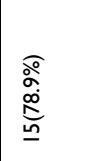 & & 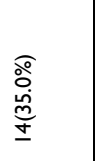 & 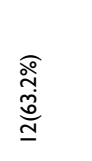 & 商 & 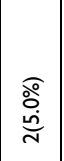 & 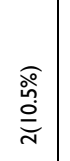 & 0 & 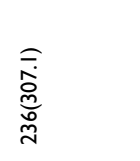 & 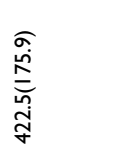 & 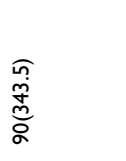 \\
\hline & \begin{tabular}{|l}
$\overline{\overline{\mathrm{N}}}$ \\
$\overline{\mathrm{g}}$ \\
ठे
\end{tabular} & $\ddot{q}$ & $\stackrel{ \pm}{\sim}$ & $\bar{\lambda}$ & $\bar{\sim}$ & 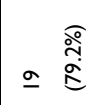 & 高 & 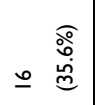 & 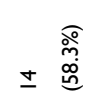 & 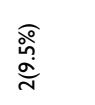 & 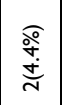 & 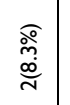 & 。 & 옹 & 电兽 & 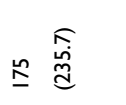 \\
\hline \multirow{5}{*}{ 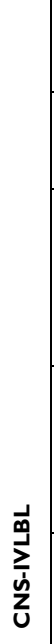 } & 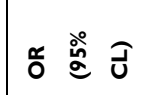 & . & . & . & . & & . & . & . & . & 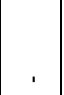 & . & , & 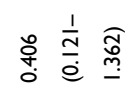 & 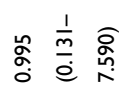 & 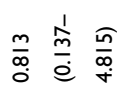 \\
\hline & $a$ & \multicolumn{3}{|l|}{ 蒙 } & $\frac{+\overline{0}}{0}$ & 京 & . & 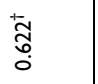 & $\begin{array}{l}\text {. } \\
\stackrel{\circ}{\infty} \\
\text { o }\end{array}$ & . & $\stackrel{+}{\bar{n}}$ & 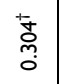 & . & $\frac{\text { 等 }}{0}$ & 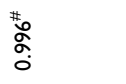 & . \\
\hline & 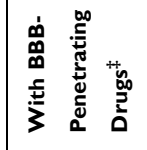 & $=$ & 은 & - & 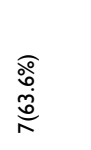 & 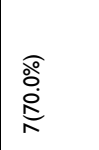 & 0 & 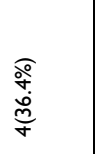 & 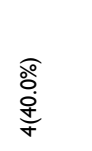 & 。 & $\frac{\Im}{\stackrel{\circ}{\varrho}}$ & $\begin{array}{l}\widehat{\circ} \\
\stackrel{\circ}{\stackrel{0}{0}} \\
=\end{array}$ & 0 & 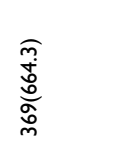 & 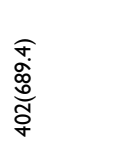 & $\stackrel{\circ}{\stackrel{\infty}{2}}$ \\
\hline & 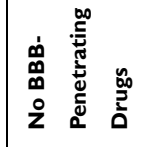 & $\therefore$ & $\stackrel{m}{m}$ & $\mathcal{F}$ & 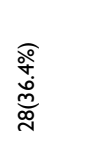 & 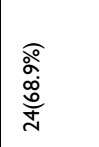 & 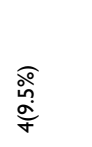 & 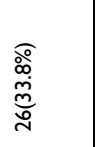 & 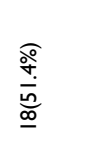 & 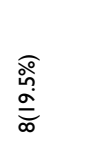 & $\begin{array}{l}\stackrel{\circ}{\circ} \\
\stackrel{\circ}{m} \\
\stackrel{m}{m}\end{array}$ & 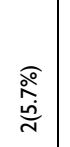 & 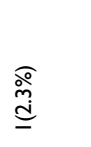 & 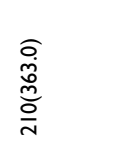 & 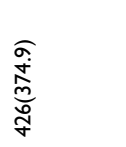 & 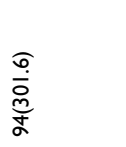 \\
\hline & $\begin{array}{l}\overline{\bar{g}} \\
\overline{0} \\
\text { ò }\end{array}$ & 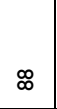 & \& & q & 亗 & 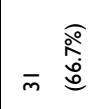 & 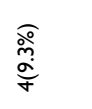 & 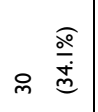 & 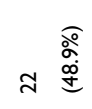 & $\infty \stackrel{\substack{\stackrel{\circ}{\circ} \\
\stackrel{\infty}{\infty}}}{=}$ & 㞼 & 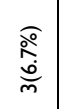 & @ָ & 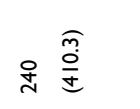 & œ & 盀言 \\
\hline 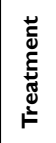 & 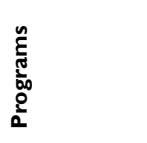 & 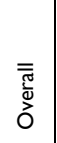 & 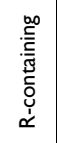 & 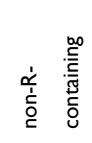 & $\begin{array}{l}\overline{\overline{\bar{v}}} \\
\bar{y} \\
\text { Oे }\end{array}$ & 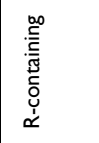 & 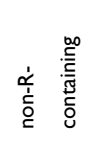 & $\begin{array}{l}\overline{\overline{\bar{v}}} \\
\overline{\mathrm{d}} \\
\overline{0}\end{array}$ & 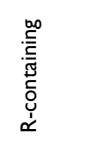 & 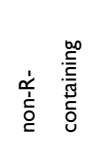 & 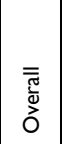 & 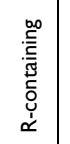 & 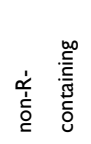 & $\begin{array}{l}\overline{\overline{\bar{\pi}}} \\
\overline{\tilde{y}} \\
\text { Oे }\end{array}$ & 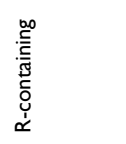 & 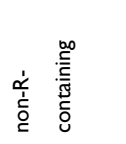 \\
\hline \multicolumn{2}{|c|}{ 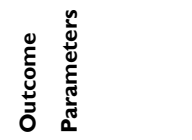 } & \multicolumn{3}{|l|}{$z$} & \multicolumn{3}{|l|}{$\begin{array}{l}\widehat{\nwarrow} \\
\dot{c} \\
\text { d̛ }\end{array}$} & \multicolumn{3}{|l|}{ 离离 } & \multicolumn{3}{|c|}{ 离颜 } & \multicolumn{3}{|l|}{ 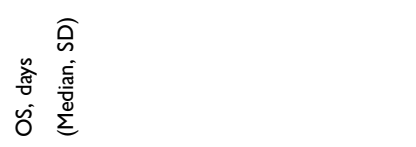 } \\
\hline
\end{tabular}


Table 5 Stratified Analyze of Predictive Factors of Time from Onset to Death

\begin{tabular}{|c|c|c|c|c|c|c|c|c|c|}
\hline \multirow{2}{*}{$\begin{array}{l}\text { Treatment } \\
\text { Groups }\end{array}$} & \multirow[t]{2}{*}{ Variables } & \multicolumn{4}{|c|}{ Univariate Cox Regression Test } & \multicolumn{4}{|c|}{ Multivariate Cox Regression Test* } \\
\hline & & $P$ value & HR & $\begin{array}{l}\text { Lower } 95 \% \\
\mathrm{Cl}\end{array}$ & $\begin{array}{l}\text { Upper 95\% } \\
\mathrm{Cl}\end{array}$ & $P$ value & HR & $\begin{array}{l}\text { Lower } 95 \% \\
\mathrm{Cl}\end{array}$ & $\begin{array}{l}\text { Upper } 95 \% \\
\mathrm{Cl}\end{array}$ \\
\hline \multirow{8}{*}{$\begin{array}{l}\text { All treatment } \\
\text { groups }\end{array}$} & Male & 0.398 & 0.801 & 0.479 & 1.340 & - & - & - & - \\
\hline & Asian variant & 0.097 & 1.670 & 0.912 & 3.060 & - & - & - & - \\
\hline & $\operatorname{Age}(\geq 70 y)$ & 0.665 & 1.129 & 0.653 & 1.951 & 0.454 & 1.327 & 0.633 & 2.783 \\
\hline & LDH ( $(\geq 700 \mathrm{U} / \mathrm{L})$ & 0.805 & 1.091 & 0.545 & 2.182 & 0.332 & 1.531 & 0.647 & 3.621 \\
\hline & Skin involvement & 0.192 & 0.619 & 0.301 & 1.272 & 0.288 & 0.634 & 0.274 & 1.470 \\
\hline & CNS involvement & 0.157 & 1.485 & 0.859 & 2.567 & 0.035 & 2.234 & 1.058 & 4.715 \\
\hline & BM involvement & 0.535 & 0.732 & 0.274 & 1.960 & 0.981 & 1.010 & 0.455 & 2.242 \\
\hline & Hemophagocytosis & 0.399 & 1.087 & 0.896 & 1.318 & 0.157 & 1.162 & 0.944 & 1.431 \\
\hline \multirow[t]{8}{*}{$\mathrm{R}-\mathrm{CT}$ group } & Male & 0.472 & 0.728 & 0.306 & 1.730 & - & - & - & - \\
\hline & Asian variant & 0.676 & 1.185 & 0.535 & 2.625 & - & - & - & - \\
\hline & $\operatorname{Age}(\geq 70 y)$ & 0.954 & 1.029 & 0.399 & 2.653 & 0.904 & 0.918 & 0.227 & 3.715 \\
\hline & LDH ( $\geq 700$ U/L) & 0.074 & 2.292 & 0.922 & 5.697 & 0.952 & 1.047 & 0.232 & 4.722 \\
\hline & Skin involvement & 0.415 & 0.689 & 0.281 & 1.688 & 0.402 & 0.409 & 0.051 & 3.307 \\
\hline & CNS involvement & 0.286 & 1.479 & 0.721 & 3.033 & 0.046 & 4.572 & 1.026 & 20.370 \\
\hline & BM involvement & 0.531 & 1.319 & 0.554 & 3.140 & 0.769 & 1.249 & 0.284 & 5.493 \\
\hline & HPS & 0.012 & 1.295 & 1.058 & 1.585 & 0.001 & 1.543 & 1.199 & 1.987 \\
\hline \multirow[t]{8}{*}{ Non-R-CT groups } & Male & 0.777 & 0.906 & 0.459 & 1.788 & - & - & - & - \\
\hline & Asian variant & 0.058 & 3.307 & 0.960 & 11.388 & - & - & - & - \\
\hline & $\operatorname{Age}(\geq 70 y)$ & 0.796 & 1.096 & 0.547 & 2.193 & 0.038 & 3.375 & 1.073 & 10.616 \\
\hline & LDH ( $\geq 700$ U/L) & 0.485 & 0.672 & 0.220 & 2.054 & 0.021 & 4.101 & 1.233 & 13.644 \\
\hline & Skin involvement & 0.231 & 0.406 & 0.093 & 1.776 & 0.034 & 0.256 & 0.072 & 0.903 \\
\hline & CNS involvement & 0.199 & 1.838 & 0.726 & 4.648 & $0.46 I$ & 1.456 & 0.537 & 3.953 \\
\hline & BM involvement & 0.529 & 1.238 & 0.637 & 2.409 & 0.416 & 0.600 & 0.175 & 2.059 \\
\hline & Hemophagocytosis & 0.676 & 0.844 & 0.381 & 1.8693 & 0.147 & 0.366 & 0.094 & 1.422 \\
\hline
\end{tabular}

Notes: *In the light of previous studies and comparison results between treatment groups (Supplementary Table I), we chose age $\geq 70 y$, LDH $\geq 700 U / L$, skin, CNS, and BM involvement and hemophagocytosis as potential predictive factors to enter a multivariate Cox regression test. In the univariate Cox regression test, 145 Patients were included in the analysis after excluding those diagnosed postmodern or with incomplete treatment data. In the multivariate Cox regression test, 46 other patients were further excluded for missing data of LDH and organs involvement data (detailed analysis of the missing data is showed in Supplementary Table 5). ${ }^{-}$Stands for not appliable for analysis.

Abbreviations: LDH, lactate dehydrogenase; CNS, central nervous system; BM, bone marrow; HPS, haemophagocytic syndrome.

significance, contradicting the previous results of a metaanalysis of 740 patients with IVL. ${ }^{15}$ As the age distribution was similar between the two studies, the contradiction may be associated with differences in sample size. Skin lesions at onset, based on previous findings, are associated with longer median survival, which is possibly explained by the feasibility of early-stage biopsy and diagnosis. ${ }^{15,20}$ Contrarily, in our study, skin involvement only had a protective effect in the non-R-CT group. This can possibly be explained by the fact that the protective effect of rituximab-containing treatment is much stronger than that of skin involvement; thus, the relatively weak effect of skin involvement was not evident in the R-CT group. HPS, which is known as a feature of Asian-variant IVLBCL, was identified as an unfavorable predictive factor in the R-CT group in our data, which has not been reported previously. This result suggests that R-CT treatment may be less effective in patients with HPS, and the mechanism deserves further exploration. Overall, the outcome of patients with IVLBCL is affected by several factors during the course of the disease, and the complex progression pattern remains unexplained.

This study had several limitations. In particular, the cases were not taken from the same study, and standardization regarding the reporting criteria, duration of follow-up, or treatment protocol was not performed. In addition, the original data featured missing values, which may have led to deviation of the results to some extent. However, some vital information such as the involved organs, LDH levels, treatment protocols, and survival time was provided in detail in most cases, which ensured the reliability of the results. Moreover, we used various methods to improve the integrity 
and accuracy of the data, such as balancing the patient source (from large series or not) between the groups, and other measures were detailed in the Methods section. Hopefully, this research will be helpful for in-depth recognition of the disease, especially for the treatment of CNS-involved cases.

\section{Conclusion and Prospect}

Our data suggest that rituximab-containing chemotherapy can improve the outcomes of patients with IVLBCL, but the prognosis remains unsatisfactory. Treatment regimens containing BBB-penetrating drugs failed to improve outcomes in patients with CNS-involved IVLBCL. LDH levels, CNS involvement, and HPS were identified as risk factors for poor outcomes.

Targeted therapeutic drugs are highly expected to improve the outcomes of IVLBCL treatment in the future. Thus, further research is needed to focus on the genotypephenotype spectrum of the disease and identify vital molecular markers of the pathogenic pathway.

\section{Disclosure}

The authors report no funding and no conflicts of interest for this work.

\section{References}

1. Swerdlow SH, Campo E, Lee Harris N. WHO classification of tumours of haematopoietic and lymphoid tissues. Classification Tumours. 2017;317-318.

2. Shimada K, Kinoshita T, Naoe T, Nakamura S. Presentation and management of intravascular large B-cell lymphoma. Lancet Oncol. 2009;10:895-902. doi:10.1016/S1470-2045(09)70140-8

3. Zuckerman D, Seliem R, Hochberg E. Intravascular lymphoma: the oncologist's “great imitator". Oncologist. 2006;11(5):496-502. doi:10.1634/theoncologist.11-5-496

4. Orwat DE, Batalis NI. Intravascular large B-cell lymphoma. Arch Pathol Lab Med. 2012;136(3):333-338. doi:10.5858/arpa.2010-0747RS

5. Brunet V, Marouan S, Routy JP, et al. Retrospective study of intravascular large B-cell lymphoma cases diagnosed in Quebec: a retrospective study of 29 case reports. Medicine (Baltimore). 2017;96(5):e5985. doi:10.1097/MD.0000000000005985

6. Lin TK, Yeh TH, Hsu PW, et al. Primary central nervous system lymphomas of the brain: a retrospective analysis in a single institution. World Neurosurg. 2017;103:550-556. doi:10.1016/j. wneu.2017.03.095

Cancer Management and Research

\section{Publish your work in this journal}

Cancer Management and Research is an international, peer-reviewed open access journal focusing on cancer research and the optimal use of preventative and integrated treatment interventions to achieve improved outcomes, enhanced survival and quality of life for the cancer patient.
7. Caimi PF, Hill BT, Hsi ED, Smith MR. Clinical approach to diffuse large B cell lymphoma. Blood Rev. 2016;30(6):477-491. doi:10.1016/ j.blre.2016.06.003

8. Roschewski M, Staudt LM, Wilson WH. Diffuse large B-cell lymphoma-treatment approaches in the molecular era. Nat Rev Clin Oncol. 2014;11(1):12-23. doi:10.1038/nrclinonc.2013.197

9. Shimada K, Matsue K, Yamamoto K, et al. Retrospective analysis of intravascular large B-cell lymphoma treated with rituximab-containing chemotherapy as reported by the IVL study group in Japan. J Clin Oncol. 2008;26(19):3189-3195. doi:10.1200/ JCO.2007.15.4278

10. Su DW, Pasch W, Costales C, Siddiqi I, Mohrbacher A. Asian-variant intravascular large B-cell lymphoma. Proc (Bayl Univ Med Cent). 2017;30(2):186-189. doi:10.1080/08998280.2017.11929579

11. Fonkem E, Dayawansa S, Stroberg E, et al. Neurological presentations of intravascular lymphoma (IVL): meta-analysis of 654 patients. BMC Neurol. 2016;16:9. doi:10.1186/s12883-015-0509-8

12. Yamamoto A, Kikuchi Y, Homma K, O’Uchi T, Furui S. Characteristics of intravascular large B-cell lymphoma on cerebral MR imaging. AJNR Am J Neuroradiol. 2012;33(2):292-296. doi:10.3174/ajnr.A2770

13. Zukas A, Bennani N, Chou C, et al. Intravascular lymphoma affecting the central nervous system: features and outcomes in a case series of the primary CNS lymphoma collaborative group (IPCG) [Journal: conference Abstract]. Scottsdale, AZ: Neuro-oncology Conference: 21 st annual scientific meeting and education day of the society for neuro-oncology United states Conference start: 20161117 Conference end: 20161120; 2016;18:vi168. doi:10.1093/neuonc/now212.702.

14. Kerbauy MN, Moraes FY, Lok BH, et al. Challenges and opportunities in primary CNS lymphoma: a systematic review. Radiother Oncol. 2017;122(3):352-361. doi:10.1016/j.radonc.2016.12.033

15. Fonkem E, Lok E, Robison D, Gautam S, Wong ET. The natural history of intravascular lymphomatosis. Cancer Med. 2014;3 (4):1010-1024. doi:10.1002/cam4.269

16. Wang J, Ding W, Gao L, et al. High frequency of bone marrow involvement in intravascular large B-cell lymphoma. Int J Surg Pathol. 2017;25(2):118-126. doi:10.1177/1066896916665203

17. Kubisova K, Martanovic P, Sisovsky V, et al. Dominant neurologic symptomatology in intravascular large B-cell lymphoma. Bratisl Lek Listy. 2016;117(06):308-311.

18. Oomura M, Sakakibara N, Suzuki S, Wakita A, Mori Y, Kamimoto K. Intravascular lymphomatosis mimicking primary central nervous system lymphoma: a case report and literature review. Case Rep Neurol. 2014;6(1):101-108. doi:10.1159/000362121

19. Renjen PN, Khan NI, Gujrati Y, Kumar S. Intravascular large B-cell lymphoma confirmed by brain biopsy: a case report. BMJ Case Rep. 2013;2013.

20. Ferreri AJ, Campo E, Seymour JF, et al. Intravascular lymphoma: clinical presentation, natural history, management and prognostic factors in a series of 38 cases, with special emphasis on the 'cutaneous variant'. $B r$ J Haematol. 2004;127(2):173-183. doi:10.1111/ j.1365-2141.2004.05177.x
The manuscript management system is completely online and includes a very quick and fair peer-review system, which is all easy to use. Visit http://www.dovepress.com/testimonials.php to read real quotes from published authors.

\section{Dovepress}

(20)

